\title{
ARTigo
}

\section{Entre "reais" e "virtuais": noções sobre risco e verdade em um clube brasileiro para crossdressers*}

\author{
Anna Paula Vencato**
}

\section{Resumo}

Proponho analisar a partir das noções de "real" e "virtual" como se constrói a hierarquia dentre associadas em um clube brasileiro para crossdressers, que se organiza a partir da internet, e o quanto elas impactam as negociações e relações sociais para dentro $e$ para fora do clube na produção de "crossdressers de verdade". Também busco entender em que medida se constroem lugares diferenciados para as associadas, pautadas nas noções sociológicas de gênero, sexualidade, estigma e senioridade.

Palavras-chave: Internet, Gênero, Cross-Dressing, Sociabilidade.

\footnotetext{
* Recebido para publicação em 22 de outubro de 2013, aceito em 6 de fevereiro de 2015. Agradeço a Paula Andrews por informações sobre o início e história do clube, assim como por diversas informações acerca do período que antecedeu à organização deste. Patricia Din também foi fundamental no levantamento dessas informações. Agradeço também à Debbi pelas informações mais pontuais acerca da história da formação do clube.

** Professora Titular da Universidade Paulista - Unip e assessora de políticas LBT da Secretaria Municipal de Políticas para as Mulheres da Prefeitura de São Paulo, Brasil.apvencato@gmail.com
} 
368 Entre "reais"e "virtuais"...

Between "Real" and "Virtual": Notions of Truth and Risk in a Brazilian Club for Crossdressers

\begin{abstract}
I propose to examine how hierarchy is build among associated members from a Brazilian club of crossdressers, using the notions of "real" and "virtual". This club is organized from the internet. I still seek to understand how these concepts impact the negotiations and social relations inside and outside the club in the production of "real crossdressers". I also analyze the extent to which they build different places for different club members guided by the sociological notions of gender, sexuality, stigma and seniority.
\end{abstract}

Key Words: Internet, Gender, Cross-Dressing, Sociability. 
Para Kelly da Silva Neta (1957-2013) e Marcia Regina Moreira (1945-2015), in memoriam.

\section{Uma breve apresentação do campo}

Este texto é embasado em pesquisa realizada com homens que praticam crossdressing, ao longo dos anos de 2007 a 2009. A questão central que norteou a investigação foi entender como pessoas que se identificam como praticantes de crossdressing, ou crossdressers, negociam o se montar ou se vestir de mulher em diversas instâncias de suas vidas. Essas instâncias compreendem as relações com família, trabalho, relações afetivas e/ou conjugais, etc. Também se buscou compreender como esses homens articulam noções de gênero na produção das mulheres que constroem, e como as produzem a partir de noções de feminilidade específicas que retiram daquilo que acreditam ser ou veem como legitimamente feminino.

Embora as significações sobre o termo possam variar, grosso modo, uma pessoa que se identifica como crossdresser pode ser definida como alguém que eventualmente usa ou se produz com roupas e acessórios tidos como do sexo oposto ao que lhe foi assignado ao nascer. Crossdressers não são mulheres e não se veem como tal. De forma rápida, poder-se-ia dizer que são homens que se vestem de mulher ou que efetivam o desejo de se vestir com roupas e acessórios femininos, embora o que indicam como significado para o crossdressing seja algo um tanto mais complexo que isso, e a noção de feminino que usam para se montar seja bastante peculiar. É uma montagem transitória, realizada em alguns momentos específicos, que envolve graus variados de intervenção corporal, dependendo do que se pretende em termos de resultado final daquela produção. As crossdressers não são e nem procuram ser uma caricatura de mulher embora em alguns momentos a noção de uma espécie de paródia do real pareça informar suas montagens, atitudes e, sobretudo, sociabilidades. 
Há uma ampla gama de possibilidades do que possa ser considerado crossdressing. Minha pesquisa, de base etnográfica, foi realizada basicamente com homens que o praticam em eventos do Brazilian Crossdresser Club (BCC) ou organizados por membros desse clube e também na internet. Na internet, o contato com crossdressers se deu desde o início do ano de 2007. Com o BCC "real" passei a ter contato no final do ano de $2007^{1} e$ acompanhei diversos eventos locais semanais em São Paulo (jantares, aniversários, festas), Rio de Janeiro e outros eventos maiores do clube ao longo do ano de 2008 (que reúnem membros de diversas cidades do Brasil e geralmente acontecem em hotéis/pousadas que são fechadas para o evento). Também realizei entrevistas com pessoas de dentro e de fora do $\mathrm{BCC}$, que se identificam como crossdressers ou $\mathrm{S} / \mathrm{O}^{2}{ }^{2}$ e pessoas que prestam serviços para $\mathrm{cds}^{3}$. Este artigo versa sobre as experiências e visões de mundo das crossdressers "reais" que fazem parte do clube pesquisado. Assim, reflete apenas suas perspectivas sobre aquelas que consideram virtuais. Não tive oportunidade de coletar depoimentos das associadas virtuais do clube sobre suas experiências.

Pode-se argumentar que as diversas formas de praticar crossdressing também assumem significados específicos em diferentes grupos. Esses grupos não costumam ser homogêneos $e$,

${ }^{1}$ Ao contrário do caminho percorrido por uma crossdresser "nova" no clube, só depois de ir a eventos do clube passei a participar da lista de discussão "virtual". Foi bastante tempo depois que ingressei também no "fórum real". Enquanto pesquisadora pude acompanhar ambos os fóruns, algo que não é permitido às mulheres que frequentam os eventos do clube, que ficam restritas ao "fórum real".

2 Supportive Opposite, ou $S / O$, "é uma pessoa do sexo oposto que apoia a prática Crossdresser. Pode ser uma amiga, namorada, esposa, irmã, prima... Importante ressaltar que é alguém que APOIA, não só que aceita" (definição retirada de uma comunidade para S/O's em uma rede social, em 15/06/2008). É comum, contudo, dentre as pessoas com que venho tendo contato, que as $S / O$ 's sejam esposas ou namoradas. De qualquer modo, nem toda crossdresser tem uma $S / O$.

${ }^{3}$ Cd é diminutivo de crossdresser. Cding é diminutivo de crossdressing. 
por vezes, as definições do que se está fazendo varia de acordo com os elementos sociais e subjetivos de que uma pessoa que se veste do outro sexo possa lançar mão. Dentro desses diferentes grupos, os tipos de montagem são diversos tanto em grau de publicização da prática quanto em graus de intervenção $e$ mudança corporal. As variações se dão de acordo com o que desejam como resultado final do se vestir de mulher e também da possibilidade de investir mais ou menos economicamente no coling.

As crossdressers em seus cotidianos estão inseridas em contextos sociológicos que exigem delas posturas diversificadas frente às coisas da vida, como quaisquer outros indivíduos (conforme Goffman, 2005). O crossdressing seria, nesse contexto, uma coisa a mais - mesmo que não qualquer coisa, posto que é uma dimensão que sublinham ser importante - para negociarem e que em diferentes instâncias de suas vidas pode vir a ter espaço ou não. O que pretendo mostrar aqui é como esses homens mobilizam aspectos de sua vida montada e desmontada na prática do crossdressing, e como estas negociações que empreendem são acionadas nas distinções que fazem entre associadas reais $e$ virtuais do clube de que fazem parte. Assim, do mesmo modo que negociam em suas vidas, nas diversas inserções que tenham, a efetivação do desejo de se montar, em sua sociabilidade online acionam elementos dessa negociação que tornam algumas formas de viver estas experiências legítimas e outras indesejáveis, mesmo em um campo de possível proteção via anonimato, a internet.

\section{O Brazilian Crossdresser Club}

O Brazilian Crossdresser Club possui membros de vários locais do Brasil e de diversas faixas etárias, agregando homens que "têm a fantasia de usar roupas do sexo oposto (crossdressing)" ${ }^{4}$ ou, grosso modo, se vestem de mulher. Como a

4 Muitas das informações sobre a estrutura e a organização do clube foram inicialmente retiradas de sua página na internet (www.bccclub.com.br), em acessos diversos ao longo do andamento desta pesquisa. Como as informações 
organização inicial do clube se dá pela internet, a página torna-se um importante veículo não apenas para entender o funcionamento do grupo, mas também para agregar novos membros, difundir o que entendem por crossdressing e estabelecer regras do que é tido como desejável e/ou indesejável para quem quer associar-se a ele. Logo na primeira página ${ }^{5}$ do clube na internet, encontram-se as informações de que o BCC foi fundado em 15 de maio de 1997 e é "o primeiro clube voltado para crossdressers e transgêneros ${ }^{6}$ do Brasil", informação seguida de um aviso em destaque de que aquele não é um site de conteúdo erótico. Como já foi dito, o BCC é um clube que se organizou pela internet. Algumas de suas idealizadoras já haviam se encontrado

citadas aqui dizem respeito ao período que vai de 1997 a 2005, o site não necessariamente contém dados que correspondem ao atual momento do clube ou a política da diretoria em exercício depois desta data. Para uma análise da página do $\mathrm{BCC}$ e de como ela possibilitou o encontro de um grupo estigmatizado composto por homens que se vestem de mulher, ver PRIMO, A. F. T.; PEREIRA, V. A.; FreitAS, A. (2000). Para os autores, a internet é o espaço que torna possível que estas pessoas sustentem uma identidade que não corresponde à que usam em sua "vida real". Também argumentam que "... a comunidade virtual do BCC formou-se e fortaleceu-se não apenas pela ausência de espaços urbanos que os acolhesse, mas também em razão do preconceito e estigma social" (PRIMO; PEREIRA; FREITAS, 2000:288, tradução nossa). O texto fala do clube como um espaço em que suas integrantes - reunidas em torno de um segredo compartilhado e que mantêm oculto - procuram amizades, apoio e comunicação aberta. $\mathrm{O}$ argumento foca-se, contudo, mais na análise da constituição de uma comunidade virtual do que propriamente na análise do crossdressing.

${ }^{5}$ É nela que estão disponíveis o Regimento Interno do clube, a ficha de inscrição no clube, além das páginas com os perfis das associadas, entre outros conteúdos focados nos interesses do clube. Alguns dos são produzidos pelas próprias associadas.

${ }^{6}$ A descrição provida pela página do clube utilizando as duas categorias sugere uma distinção entre elas. De modo geral, para o grupo, transgênero seria uma classificação mais geral para pessoas que usam roupas que socialmente pertencem ao sexo oposto do sexo do nascimento. Isso engloba, nesse contexto, travestis, transexuais e crossdressers - o que implica em dizer que crossdresser seria uma categoria específica que está dentro de uma outra com característica mais genérica. Isso não significa, contudo, que não se entenda que cada uma dessas categorias tenha suas especificidades e formas de ser/estar no mundo diferenciadas entre si. 
pessoalmente em momentos que antecederam à formação do clube, $e$ nesses encontros presenciais de algumas delas foi viabilizada a criação de um clube virtual para divulgar o que era crossdressing e reunir pessoas que compartilhassem desse desejo e dessa prática. ${ }^{7}$ Antes, conta-se, era comum que crossdressers, ou travestis secretos, como algumas se chamavam antes de ter contato com o termo em inglês, fizessem uso da sessão de cartas de algumas revistas de conteúdo erótico, sobretudo a Revista Private, ainda em circulação hoje, para se corresponderem. Algumas crossdressers que se correspondiam através desses anúncios mantinham caixas postais nos Correios - de preferência naquelas agências menos movimentadas e mais distantes de suas residências e/ou locais de trabalho. Há relatos de que, em alguns casos, uma vez "descobertas" pelos funcionários da instituição, "eram sacaneadas" e muitas das coisas que enviavam umas às outras (revistas, fotos, calcinhas e outros acessórios/roupas) "sumiam na mão" deles. O uso dessas caixas postais, conforme afirmam as interlocutoras deste trabalho, precedeu o uso que, mais tarde, se passou a fazer dos correios eletrônicos. Assim como ocorre dentre o público BDSM pesquisado por Regina Facchini (2008), a internet e suas possibilidades como comunidades, listas $e$ redes sociais - além dos sites usados para encontros ou pegação ${ }^{8}$ - ocupa um lugar central na experiência das crossdressers que pesquisei. Ela abre um caminho fundamental para que conheçam outras pessoas que compartilham de seus desejos e práticas e que torna possível falar sobre essa experiência, sobre os lugares em que se pode frequentar sem medos, de forma facilitada e, em geral, sem a necessidade de expor-se.

\footnotetext{
7 A história "oficial" sobre o início do clube consta na página do BCC na internet no DVD comemorativo de dez anos de sua fundação [http://www.bccclub.com.br/bcc.htm - acesso em: 20 ago 2008].

8 É extemporâneo a esta pesquisa o uso dos aplicativos de celular para encontros. Contudo, uma série de pesquisas sobre esse tema vem despontando $e$ conforma um novo locus de pesquisa e análise sobre como diferentes pessoas experienciam o gênero $e$ as sexualidades. Alguns desses trabalhos são o de Miskolci (2013, 2014) e Padilha (2014).
} 
O número de associadas do BCC é flutuante e depende, sobretudo, das simpatias ou antipatias angariadas na sociabilidade do grupo. É comum ter-se um aumento de associações quando pessoas da diretoria do clube empreendem idas a locais frequentados por crossdressers, como festas fetichistas e/ou direcionadas a essa prática ou, mesmo, bares e restaurantes tidos como "GLS". ${ }^{9}$ Também é comum que divergências de opinião e posicionamento nas listas de discussão do clube - que ocorrem muito raramente em momentos presenciais - impliquem em pedidos de saída. ${ }^{10}$

Divergências outras acerca do que deve ser o clube, do que é ser crossdresser de verdade ou os limites e peculiaridades do que é ser crossdresser, travesti ou transexual também são objeto de brigas, disputas e saídas do clube. Outra razão apontada para se deixar o BCC é a perda de sentido da participação, que pode se dar, entre outros motivos, porque a pessoa "não precisa mais do clube para vivenciar seu crossdressing" ou passa a se identificar como travesti ou transexual e o clube não mais contempla coisas

9 Sigla de Gays, Lésbicas e Simpatizantes.

${ }^{10}$ Houve, há alguns anos, um processo de recadastramento em que quem não se manifestou ficou fora do clube. Mais recentemente, uma mudança do diretório da lista resultou na perda de mais associadas. Outra influência na entrada e saída de associadas do clube, ao longo da pesquisa, foi a polêmica em torno de se a diretoria deveria ou não conceder entrevistas à mídia impressa ou televisiva em nome do BCC. Contava-se que o acesso ao site aumentara muito desde que se iniciaram as aparições na mídia. De fato o clube passou a ser mais divulgado com essas aparições, o que resultou num aumento de associações nos períodos em que apareciam na TV, em revistas ou em jornais. Por outro lado, diversas associadas mais antigas acabaram se desligando por não concordar com a forma como se estava expondo o crossdressing e o clube nessas matérias, ou por terem sido reconhecidas na foto de seu perfil no site do clube, ou ainda por não quererem arriscar serem reconhecidas pelo medo das consequências da exposição do crossdressing. Após esse período de "entrevistas" esmorecer, por razões que foram da falta de respeito dos/as jornalistas até a falta de sentido daquilo, o número de novas associações voltou a cair. Há de se considerar, contudo, que grande parte das pessoas que se associam a qualquer tempo ao $\mathrm{BCC}$ ou logo deixam o clube ou, muitas vezes, nem sequer chegam a participar efetivamente. 
que lhe interessem dada a nova situação de vida. Embates em torno das regras das listas de discussão e do comportamento de associadas dentro delas, assim como divergências sobre as regras do clube costumam causar debates calorosos sazonalmente e, algumas pessoas, caso "ofendidas", optam por sair do clube.

Há ainda casos em que descumprir as regras leva a um julgamento/consenso do C.E.A. (Comissão de Ética e Avaliação) pelo desligamento da associada, seja ela real ou virtual, que é então retirada das listas e desassociada do clube. Uma das regras mais caras ao clube é a que proíbe as associadas de encaminhar para "fora das listas" qualquer mensagem nela postada. O descumprimento dessa regra, quando comprovado, resulta na expulsão imediata. Até porque, o clube se organiza em torno da preservação da confidencialidade e do segredo acerca da vida dupla de suas associadas (Vencato, 2009a, 2013). Há a possibilidade de regresso, contudo, desde que haja um novo processo de avaliação da entrada. As razões da saída também são levadas em conta na nova submissão de associação, podendo inclusive resultar na não aprovação daquela que deseja retornar ao clube. De qualquer modo, conforme me foi dito algumas vezes em tom de confidência, a distribuição das regras no clube obedece mais à lógica de simpatias e/ou antipatias das diretoras/C.E.A. em relação à associada do que propriamente a um princípio de isonomia. Nos termos de algumas, a regra vai muito ao sentido do dito popular "aos meus amigos tudo, aos meus inimigos a lei". Isso parece ser uma constante na história do clube, não tendo relação com uma diretoria apenas: pelos relatos de associadas mais antigas, essa prática perpassou e ainda perpassa a política de todas as diretorias que o clube já teve.

\section{As listas de discussão do BCC}

O BCC tem várias listas de discussão, com níveis diversos de acesso. Há listas fechadas, como aquelas do grupo do Le Closet ${ }^{11}$

${ }^{11}$ Tanto o Le Closet do Rio de Janeiro quanto o de São Paulo tinham lista própria de discussão, fechada para membros associados a ele. O Le Closet é um 
ou de algumas regionais do clube ${ }^{12}$. As principais listas de discussão são o Fórum Real e o Fórum Virtual do Brazilian Crossdresser Club. Tive acesso às duas ao longo do trabalho de pesquisa, em momentos distintos. Quando preenchi o cadastro de pedido de associação ao clube fui inserida no Fórum Virtual, em que permaneci por alguns meses, até o $\mathrm{HeF}^{13}$ de 2008, quando foi

apartamento utilizado para que as pessoas possam se montar e deixar suas coisas, facilitando assim a vida de quem não tem como fazer isso em casa ou na cidade em que mora. Porém, não são apenas pessoas que não podem guardar suas coisas em casa que fazem parte do Le Closet. A maior parte das pessoas que faz parte dele tem outro armário em casa. Há quem nem faça uso do armário que lhe é destinado no apartamento. Consiste em uma iniciativa de um grupo de no máximo doze pessoas, que fazem, necessariamente, parte do BCC como associadas reais, mas não é algo "do clube". Havia um no Arouche/São Paulo e outro, mais antigo, na Lapa/Rio de Janeiro, e um convênio entre os dois, possibilitando que associadas de um ou de outro pudessem usar seus espaços quando em viagem. Antes da fundação do Le Closet São Paulo, houve um apartamento com um propósito semelhante, chamado de A Cage (referência ao filme de temática transgênera La Cage aux Folles, cujo nome no Brasil é A gaiola das Loucas), locado por três "fundadoras do clube" na Rua Oscar Freire. A Cage permaneceu ativa por anos, apesar da fundação do Le Closet São Paulo. Hoje nem a Cage, nem o Le Closet Rio estão mais em funcionamento.

${ }^{12}$ As regionais são braços do BCC, que estão localizados em outras regiões/cidades brasileiras "fora de São Paulo", local onde o clube "nasceu" e se encontra a maior parte das associadas. Embora no site constem seis grupos regionais, apenas alguns estavam em funcionamento durante meu trabalho de pesquisa. Os grupos listados são o Rio's Ladies (Rio de Janeiro), o Pampa's Girls (Rio Grande do Sul e Santa Catarina), o Red Feet's Ladies (Paraná), o Chese Bred's Girls (Minas Gerais), o Band's Girls (São Paulo) e o CandanGirls (Distrito Federal). De acordo com uma das fundadoras do clube, criar essas sedes em outros lugares "foi uma ideia que surgiu para facilitar a regionalização do BCC. Isso ajuda as meninas que são de um determinado estado a fazerem contato com mais facilidade com a parte REAL do clube. As regionais respondem ao $\mathrm{BCC}$, não têm autonomia para criar regras ou leis. Podem, no máximo, ter suas pequenas regrinhas desde que não infrinjam as regras do $\mathrm{BCC}$ " (Deborah Cristina, 28/07/2008). A maior parte das regionais não possui listas separadas da do clube. Na época da pesquisa, apenas as regionais do Rio Grande do Sul e do Paraná possuíam listas próprias. Os nomes estão grafados aqui do mesmo modo como aparecem na página do clube.

${ }^{13} \mathrm{HeF}$ ou Holiday en Femme é o principal e mais importante evento do clube, que acontece anualmente em uma pousada ao longo de um final de semana. $\mathrm{O}$ 
decidido que eu poderia também participar do Fórum Real. Uma das razões que me foram dadas para essa passagem é a de que eu "participava de mais eventos do clube que muitas associadas crossdressers".

A lista virtual engloba associadas que tenham sido aprovadas pela Comissão de Ética e Avaliação (C.E.A.) ao pedirem para se cadastrarem através de ficha de associação. Se houver interesse da associada em se tornar real, ela deve submeter-se às normas do clube para tal ${ }^{14}$ e, só então, terá acesso a esse fórum.

evento é inspirado em outro homônimo realizado pelo clube estadunense de crossdressers chamado Tri-Ess. É um evento muito esperado pelas associadas, em que se fecha um hotel apenas para elas, para que possam se montar longe de olhos curiosos durante o período. Até por ser o principal evento promovido pelo clube, em torno dele sempre são geradas diversas expectativas e ele é tema recorrente ao longo do ano entre uma e outra edição. $\mathrm{O}$ evento não tem sede fixa, podendo circular entre cidades, hotéis e estados, desde que respeitados os critérios de privacidade necessários e que se tenha algum cuidado para que o lugar seja acessível à maior parte das associadas (considerando objetivamente que a maior parte das associadas encontra-se na região sudeste e, entre essas, a maioria reside no estado de São Paulo). Para ir ao $\mathrm{HeF}$ é preciso pagar uma taxa que, em geral, dá direito a hospedagem e alimentação ao longo do evento. Como é quase sempre realizado em alguma pousada do interior paulista, a taxa também inclui o transporte de ônibus a partir da cidade de São Paulo. O evento é organizado sempre por uma associada real do clube, e é nele que se realiza anualmente a assembléia geral, em que são votadas novas propostas sobre os rumos futuros do clube, assim como se elege a nova diretoria. O primeiro HEF foi realizado em 1999 e de lá pra cá tem sido feito uma vez por ano. Ao evento podem ir associadas que sejam reais, ou seja, que já tenham convivido com outras reais e comprovado que são realmente crossdressers. Nesse contexto, para uma associada virtual do clube ir ao $\mathrm{HeF}$ ela precisa, necessariamente, tornar-se real primeiro. Outros eventos do clube, como as $c d$ sessions ou festas organizadas pelas associadas dispensam essa regra.

${ }^{14}$ Os passos são: ser uma associada virtual, marcar uma $c d$ session com outras associadas reais. Montar-se com as próprias roupas e acessórios. Tirar uma foto de corpo inteiro com essas associadas, a ser postada no fórum real como comprovação da passagem de categoria. As reais presentes encaminham a foto ao C.E.A. que procede a expedição do "diploma de real", também postado no fórum real, concomitantemente com a associação da nova integrante na lista real $e$ sua apresentação às demais reais. Nessas $c d$ sessions em que associadas se tornam reais, o normal é que se montem em um hotel e/ou local disponibilizado 
Assim, a lista real é composta por pessoas que sejam conhecidas "pessoalmente" por outras associadas. De qualquer modo, isso não é visto sem desconfiança por algumas cds. Uma interlocutora argumentou que, dado o número de associadas do clube, mesmo estando no fórum real, muitas associadas são desconhecidas da maioria. Nesse ponto, ela pondera sobre as pessoas que acessam essa lista: "reais para quem?". De acordo com ela, não há garantias de segurança mesmo no fórum real, uma vez que, assim como no virtual, boa parte das associadas não passa de "ilustres desconhecidas" (dela e da maioria).

As $S / O$ 's $G G^{15}$ do clube participam apenas do fórum real. Mulheres trans e travestis podem participar de ambos os fóruns, a menos que sejam apenas virtuais. Algumas S/O's desconfiam que estejam apenas no fórum real porque as cds buscam controlar o acesso delas ao que se diz ou se discute naquele espaço. As cds dizem que as $S / O$ 's não estão no fórum virtual para protegê-las do fato de que naquele espaço elas não têm ideia de quem são a maior parte das pessoas. Também dizem que é uma medida para proteger as cds de uma possível exposição ao lado delas que, por não estarem montadas, são facilmente reconhecíveis. De fato, o conteúdo das mensagens dos fóruns é diferenciado. Enquanto no fórum real se fala mais sobre encontros entre as associadas, enviam-se fotos de $c d$ sessions ${ }^{16}$, divulgações de eventos e festas,

por alguma delas e depois sigam para a rua, um bar ou restaurante, ou seja, deve-se circular em um ambiente público montada.

${ }^{15}$ GG ou Genetic Girls/Mulheres Genéticas é um termo que as associadas do clube utilizam com frequência para falar das mulheres que, nos seus termos, "nascem mulheres". Mesmo que o termo cisgênero seja usado frequentemente nos dias atuais para se referir a pessoas não que não se identificam como transgêneras, especialmente dentro do movimento trans, o termo cisgênero não teve penetração no BCC, que continua lançando mão do termo GG. Uma explicação possível para este uso é a pouca ou nenhuma participação da maior parte das associadas do BCC em movimentos sociais.

${ }^{16}$ Evento de congregação proposto como iniciativa individual de alguma associada. Pode ser realizado em bares, festas, restaurantes, em apartamentos "de se montar" como o Le Closet ou, mesmo, em suas casas. Em geral é nessas 
no fórum virtual a pauta gira mais em torno de debates sobre a experiência de se montar, a (falta de) compreensão das mulheres em geral, os medos e prazeres relativos à prática etc. É como se o primeiro funcionasse mais como um roteiro cultural e o segundo para falar sobre a experiência do crossdressing. Nesse contexto, é possível afirmar também que no fórum virtual, apesar das recomendações sobre os riscos da exposição, apresenta temas relativos à subjetividade das associadas e experiências pessoais relativas à montagem ou como a negociam em suas vidas. $\mathrm{O}$ mesmo não ocorre no fórum real, que é acompanhado por algumas das esposas e/ou S/O's. Algumas mensagens, contudo, circulam por ambos os fóruns.

Espera-se das associadas que leiam e participem ativamente dos fóruns, desde que seguidas algumas regras de conduta. Isso pode ser observado nas intervenções da moderação quando algumas discussões ocorrem ou nas assinaturas que acompanham as mensagens enviadas de cada um dos fóruns dispostas a seguir:

Somos associadas REAIS...

Aqui espera-se uma diferença de atitude e de pensar de cada uma de nós. Se somos mulheres fortes e críticas, mostremos isto com opiniões que ajudem o bem comum; o crossdressing de todas nós.

Felicidades.... sempre!!

BCC... [assinatura do Fórum Real]

Associada...

Lembre-se que és responsável pela tua simpatia e pela feminilidade. Todas nós aspiramos sermos femininas, vamos agir sempre como tais.

A tua participação é importante...

Obrigado por postar.

BCC Brazilian Crossdresser Club [assinatura do Fórum Virtual]

ocasiões que as associadas virtuais são apresentadas às reais, podendo tornar-se uma delas. 
Durante a fase inicial do clube, quando se priorizava o contato virtual, a lista desempenhava um papel central na sociabilidade das associadas. Isso me foi relatado por uma das fundadoras do BCC, que chegou a afirmar que as outras diretorias "são firulas apenas", uma vez que "quem mandava" no clube, quem de fato "detinha poder", eram aquelas pessoas, mesmo que membros da diretoria, que tinham a senha de acesso para gerenciar a página $e$ as listas de discussão. Num primeiro momento havia apenas uma lista. Foi bem mais tarde que se criou a lista para as pessoas que "se conheciam pessoalmente". Contase que essa divisão não se deu sem a acusação de uma postura separatista das pessoas que administravam o clube à época. Uma das principais diretoras daquele período admitiu que hoje vê que a separação das listas não faz tanto sentido como se pensou na época.

Em conversa por $\mathrm{MSN}^{17}$ (em 19 de julho de 2009), perguntei a atual moderadora das listas se ela as achava importantes para o grupo. Ela me respondeu, na ocasião, que não via a lista como importante, sendo apenas um veículo que canaliza a "coisa toda". O que realmente importa é o seu uso e a constância no fluxo de mensagens. Insisti e perguntei então se ela não via o fórum virtual como importante para as novatas, principalmente em razão dos relatos de experiência trocados naquele espaço, ao que me respondeu que, de fato, as listas têm esse papel importante, mas que, no caso do fórum virtual há um problema com a pulverização da mensagem, uma vez que não se sabe, na verdade, o que as virtuais são. Continuamos a conversa falando sobre as associadas virtuais:

${ }^{17}$ Como o programa foi desativado no primeiro semestre de 2013 , a definição a seguir está desatualizada. Contudo, contempla adequadamente o que era o programa quando em funcionamento: o "MSN Messenger é um programa de mensagens instantâneas criado pela Microsoft Corporation. O programa permite que um usuário da Internet se relacione com outro que tenha o mesmo programa em tempo real, podendo ter uma lista de amigos "virtuais" e acompanhar quando eles entram e saem da rede" (Wikipédia, 2008, grifo do autor [http://pt.wikipedia.org/w/index.php?title =MSN_Messenger\&oldid=10372192 _ acesso em: 20 Jun 2008]). 
- Você acha que as pessoas leem a lista, em geral?

- Acho!!... E como aquilo é uma Sodoma e Gomorra, fica difícil você dar atenção para qualquer uma. A gente se desdobra é quando 'vê' que uma delas, lá do virtual quer sair... vir pro Real, entende?

- Uhum... interessante você falar essas coisas, porque me fez ter uma ideia de que o papel da lista pode ter mudado com o passar dos anos...

- Ahhhh. Eu tb acho!! Aliás, Anninha, muitas coisas mudaram no BCC. Eu mesma venho acompanhando a mudança. Por exemplo... Uma "pseudo inocência" que tinha quando eu entrei... Já era! Eu não perdi, na verdade... Ela existia no ar, estava no $\mathrm{BCC}$. E isto, no fórum virtual, Anna. À medida que o tempo passou, as pessoas que entram lá têm um comportamento totalmente diverso. Sabe... eu penso que a qualidade das pessoas que acessam o site mudou... Agora temos fetichistas, tarados, gente mal intencionada... em uma profusão muito maior que antes. Era mais fácil controlar essas coisas com um número menor de associadas... Mas a rotatividade no BCC sempre ocorreu Anna. Fizemos um limpa em 2005. Mais de 800 "associadas" foram anuladas... Muitas associadas virtuais entram com aquele questionário limitado. Entram e, na sua maioria, constatam que o clube não oferece o que querem... Elas simplesmente deletam o e-mail e partem pra outra.

As duas listas são o centro da comunicação do grupo $e$ funcionam como um espaço de disputas e tensões, assim como um lugar de fala e escuta importante para algumas associadas, sobretudo as reais. São elas que mais opinam naqueles dois espaços. É onde se ensina às novatas como o clube funciona, o que é ser crossdressers e como uma mulher ( $c d$, nesse caso) deve agir. Nesse sentido, as virtuais seriam aquelas associadas que, por não precisarem dizer quem são desmontadas, teriam maior potencial de burlar as regras das listas e do clube. Durante todo o 
trabalho de pesquisa, foi comum a negação à ideia de uma associação entre crossdressing e fetiche. Para elas, o objetivo do clube não era proporcionar encontros sexuais para as associadas. É como se uma "crossdresser de verdade" fosse, ao mesmo tempo, um modelo de feminilidade imbuído de atributos que a tornariam atraente para outros homens, mas que, ao mesmo tempo, fosse casta e quase "assexuada".

A ideia de Sodoma e Gomorra diz respeito tanto à falta de adequação das candidatas a fazer parte do grupo seleto de "reais" quanto à possibilidade de estarem ali com propósitos distintos daquele de apenas "se montar lindamente", conforme ouvi inúmeras vezes. Ainda, sobre as virtuais sempre recaía a suspeita de que poderiam ser homens "disfarçados de cds" que procuravam encontros ou, mesmo "cds fetichistas" que queriam "transar montadas".

A aversão à ideia de que a lista pode servir para propiciar encontros sexuais entre associadas é demonstrada constantemente nos diálogos entre elas, tanto nas listas quanto fora delas. Há uma espécie de moralidade em que o prazer relativo à prática do crossdressing legítimo diz respeito a "se vestir de mulher". Como se a sexualidade fosse um botão que pode - e deve - ser desligado a partir do momento da montagem. Aquela que cedem aos desejos sexuais - sobretudo se se relacionam com outros homens - são tidas como crossdressers falsas. Isso difere grandemente dos blogs crossdresser pesquisados por Marcela Thaís de Melo Barbosa (2014). Para a autora,

\footnotetext{
...os blogs crossdresser convertem-se em espaços de discussões sobre a prática, delineamento da categoria, espaço pessoal no qual a prática vivenciada individualmente é expressada, espaço de socialização e também inserção no mercado do sexo (Barbosa, 2014:101).
}

A vivência do crossdressing que inclua uma visão da sexualidade de si é frequentemente repreendida e desqualificada dentre as crossdressers que pesquisei. Vitor Pinheiro Grunvald 
(2014), em sua pesquisa atual, tem encontrado crossdressers na internet com o mesmo tipo de aversão: há as crossdressers de verdade, que reproduzem certo modelo de feminilidade e há as "cdzinhas", tidas como pessoas que não podem ser consideradas crossdressers por cederem a seus desejos sexuais quando montadas ou, ainda "mais grave", montarem-se justamente para esse fim.

Na lista debatem-se os significados do que é estar feminina. Isso engloba uma série de dicas sobre como se portar ou como se vestir de modo feminino. Embora o fluxo de mensagens das duas listas seja grande ${ }^{18}$, os temas repetem-se ao longo do tempo. Os temas das conversas são parecidos com os que se conversava em comunidades do Orkut $^{19}$, embora nessas listas se fale também acerca do funcionamento do clube e da sociabilidade nos eventos e encontros realizados. Os assuntos geralmente giram em torno de aproximações ou afastamentos em relação a outras pessoas que se identificavam como travestis ou transexuais; sobre comprar roupas, maquiagens e acessórios; sobre o que é crossdressing para cada uma delas (até que ponto vai, o que é crossdressing legítimo ou não, o que é ser uma "crossdresser de verdade" e outros temas sobre os quais o consenso nunca se estabelece); dicas de hormonioterapia (hormonização cruzada) e de profissionais de saúde que, conforme relatam, atendem a esse público sem

${ }^{18}$ De junho de 2008 a junho de 2009 foram trocadas 8946 mensagens no fórum real, sendo o mês de maio de 2009 o com menor número de mensagens (293) e o de outubro de 2008, que foi o mês do evento "Olím...piadas" o com maior número (1235). O fórum virtual foi trocado de servidor no início de 2009, portando não tenho como realizar aqui um cálculo equivalente. De qualquer modo, no período que vai de fevereiro a agosto de 2009, foram trocadas 7335 mensagens. Fevereiro, mês de implantação da lista, teve o menor número de mensagens (257) e julho teve o maior fluxo delas (1569).

${ }^{19}$ Rede social criada pelo Google, bastante utilizada pelas interlocutoras de meu trabalho à época da pesquisa. Hoje, acompanhando o processo de esvaziamento que atingiu aquela rede social, muitas cds migraram para outra rede, o Facebook. Algumas das associadas mais antigas do BCC acusam as mais jovens de "ingratidão" e/ou "falta de compromisso" por participarem/interagirem mais no Facebook do que das listas do clube atualmente. 
preconceitos; indicação de alguns lugares que frequentam montadas. ${ }^{20}$ Diferente do Orkut, contudo, em que também se encontrava nas comunidades e/ou perfis a procura por relacionamentos com homens, mulheres, homens e mulheres, travestis, outras crossdressers ou outras conformações de relacionamentos, as listas do $\mathrm{BCC}$ são bastante refratárias à ideia de busca de relacionamentos erótico-afetivos por parte das associadas. A lista "não é um lugar para isso", dizem, e o descumprimento dessa regra pode levar a advertências e/ou expulsões. Circulam pelas listas, também, informações acerca de palestras, bibliografias (acadêmicas, literárias ou autobiográficas) sobre transgênero, matérias que saem na mídia sobre crossdressers, travestis e transexuais e chamadas para atividades do clube (no caso da lista real, as chamadas são feitas diretamente $e$, no caso da virtual, vêm sempre acompanhadas com um estímulo para que se passe à outra categoria de associação).

De qualquer modo, o maior número de mensagens trocadas sempre gira em torno das classificações sobre o que é ser crossdresser, os limites desta classificação os significados em geral sobre o que fazem. Essas mensagens costumam causar polêmica e algumas discussões se estendem por semanas. Quando as discussões passam de certo limite, geralmente ocorre intervenção da moderação que pede que os ânimos se acalmem. Se alguma associada julgar-se ofendida, pode pedir que o C.E.A. se manifeste a respeito da questão. Eventualmente alguma associada chega a pedir afastamento do clube durante os embates mais acalorados. Contudo, é comum também que voltem atrás dessa decisão, retornando ao clube, ou que continuem frequentando os encontros presenciais apesar de não mais retornarem às listas e/ou retomarem a associação ao clube.

\footnotetext{
${ }^{20} \mathrm{Em}$ geral, na lista, as indicações ocorrem sem muito questionamento sobre a qualidade do serviço prestado pelo/a profissional ou, mesmo, dos preços praticados. É nos encontros presenciais que essas críticas aparecem aqui e ali, muito embora também de modo esparso.
} 


\section{Considerações finais}

Em minha tese de doutorado, pesquisei as negociações sociais que envolviam a prática de vestir-se de mulher em várias instâncias da vida de homens associados a um clube brasileiro para crossdressers que se organiza de forma virtual, embora com momentos presenciais. Encontrei durante a etnografia uma hierarquização entre as que "tem coragem de sair montadas" (reais) e as que "ficam apenas no virtual" (virtuais). Para além da coragem, associava-se às reais a ideia de que eram "crossdressers de verdade" e/ou "confiáveis", enquanto as virtuais eram colocadas sob suspeita. O clube separa as reais das virtuais em duas listas de discussão distintas na internet, em que reais podem circular por ambas enquanto virtuais ficam restritas ao fórum virtual. As $\mathrm{S} / \mathrm{O}^{\prime}$ s ou esposas das reais ficam restritas apenas ao fórum real, onde supostamente estariam protegidas dos "riscos de estar no virtual". Ainda, encontrei uma série de recomendações sobre os cuidados quanto ao que se publica no fórum virtual (evitar enviar fotos, mesmo que se esteja montada nelas, ou dados sobre a vida desmontada). Contudo, também ouvi de associadas questionamentos acerca dessa distinção, assim como da potencialidade do risco ou a manutenção efetiva do segredo em ambos os fóruns.

Para as associadas que questionam que um fórum é mais seguro que o outro ser real "não é garantia de nada", já que mesmo que se tomem certas precauções, não há como saber se de fato quem está no real tem ou não "boas intenções". Algumas apontam, ainda, que esta diferença "é uma bobagem". Contudo, foi possível identificar que há uma distinção de valor entre estar numa ou noutra posição dentro do clube. Nesse contexto, percebi que é especialmente a partir das noções de real e virtual e da separação entre as associadas em duas listas de discussão distintas que se constrói a principal hierarquia estabelecida entre as associadas: aquelas que são crossdresser de verdade e as que estão apenas brincando. Essa distinção impacta profundamente as negociações e relações sociais para dentro e para fora do clube na 
produção de crossdressers "de verdade" e também de um crossdressing seguro, algo que é bastante caro para a maior parte de minhas interlocutoras.

Posso afirmar que, a construção de lugares diferenciados para as associadas está pautada nas noções sociológicas de gênero, sexualidade, estigma e senioridade no contexto pesquisado. É com o tempo e a convivência contínua que se constroem confiança e amizade, inclusive através da proteção ao segredo sobre a prática do cding. Há um caminho a ser percorrido dentro do clube, que passa do anonimato possível da virtualidade pelo reconhecimento e conquista de confiança de passar a real e mostrar-se "uma pessoa de bem" (ou seja, educada, que não tem comportamentos públicos tidos como inadequados - como bebedeiras, desrespeito às esposas de outras associadas, exageros na "galinhagem", montar-se apenas para "putaria", "não se portar como uma dama" em público etc.).

Se por um lado no $\mathrm{BCC}$ se reproduz um desejo de cisão entre aquilo que é a vivência real e a virtual em nome da manutenção da vida dupla e/ou diminuição do risco indesejável de exposição do crossdressing (Vencato, 2009a), é possível encontrar também na forma como se operacionaliza essa separação de listas e sociabilidades algum desejo de continuidade entre as duas esferas, em especial para aquelas aceitas como reais. Nem sempre a sociabilidade virtual demanda essa continuidade e, por vezes, é comum em alguns ambientes virtuais que se deseje que aquilo que se vive online permaneça online (Leitão, 2012). Contudo, essa não é uma regra seguida por todas as pessoas que interagem dentro de um mesmo universo virtual, que participam dessa sociabilidade (Gomes e Leitão, 2011). Ainda, penso que cabe aqui a análise de Richard Miskolci (2011) sobre a cisão entre "real" e "virtual" quando afirma que, quando pesquisamos na internet, é necessário estar atento para o fato de que

... o campo não tem suas fronteiras delimitadas por um site assim como precisa compreender a articulação entre online e off-line, um contínuo no qual nos inserimos assim como 
nossos sujeitos de pesquisa. Ao contrário das primeiras investigações que trabalhavam com a oposição real-virtual, atualmente se tornou quase consenso o fato de que as novas mídias não criam um universo social à parte - o qual alguns chamaram de ciberespaço (Lévy, 2005) - antes mediam e modificam a forma como vivemos nossa vida offline dentro de um contínuo articulado e interdependente (...) De qualquer forma, é compreensível que os usuários e mesmo os pesquisadores/as - ainda tendam a transferir a forma como compreendemos o mundo sem mediação digital para ele. Algo perceptível até mesmo no fato de que chamamos de sites, portanto lugares, as plataformas, pois aprendemos a nos localizar espacialmente antes de adentrar na esfera on (Richard Miskolci, 2011:15-16).

O que parece peculiar no contexto que pesquisei é que, para ser reconhecida como "de verdade" dentro $e$ fora da internet é preciso "passar a real". Durante toda a pesquisa foi notório o incentivo para que associadas virtuais dessem esse passo a frente, rumo ao "crossdressing pleno". Ou seja, o reconhecimento como alguém que "não está apenas brincando de se montar" no ciberespaço passa também pelo reconhecimento fora dele, pela ação manifesta de interagir em "carne e osso" com outras associadas, seja em eventos e/ou lugares tidos como seguros ou em festas mais abertas em que possam porventura se encontrar. Em contrapartida, só é possível tornar-se real a partir de uma inserção primeira no lugar de virtual.

Bruno Zilli (2007) discute, a partir dos trabalhos de Pierre Lévy (1996) e Jayme Aranha Filho (1995), a noção de real e virtual para os discursos de legitimação do BDSM na internet que analisou em sua dissertação de mestrado. Para ele,

o virtual é uma nova modalidade de ser. Seu meio, por definição, é o ciberespaço - uma noção que complexifica a concepção de espaço puramente físico. O ciberespaço é percebido por seus usuários como um lugar real, cuja geografia é denotada pelos termos que descrevem a forma de mover-se e localizar-se nele. (...) Tampouco o virtual $e$ 
os processos que ele engendra são percebidos como algo diferente do real. Se a própria noção de espaço se desmaterializa diante do virtual, a percepção do tempo e a noção da presença também são reformadas (Bruno Zilli, 2007:51).

Essa reflexão também pode ser utilizada para falar da divisão realizada pelas crossdressers entre virtual e real, uma vez que antes de espaços separados por fronteiras duras e fixas, funcionam como espaços contínuos. Máximo, Lacerda e Rifiotis (2008), afirmam que os fenômenos sociais que são engendrados no "ciberespaço" relacionam-se com padrões culturais construídos pelos sujeitos que estão em interação, para além de uma ideia de divisão entre online e off-line. A partir dessa perspectiva, torna-se possível compreender as práticas sociais e os significados que são atribuídos a esses dois domínios na fronteira entre e/ou no fluxo contínuo entre eles. O contexto do crossdressing se vale de expedientes muito próximos ao do BDSM pesquisados por Facchini (2008) e Zilli (2007), tanto no que concerne a sociabilidade no virtual e a sua passagem para o real, quanto ao fato de terem no espaço da internet um espaço de reconhecida importância para o "encontro com outras pessoas que compartilham dos mesmos desejos e práticas", conforme venho apontando (Vencato, 2009a, 2009b). Nesse contexto, pode-se afirmar que a experiência do grupo pesquisado tanto no espaço virtual como no espaço real são tidas como reais, já que fundamentais para a própria construção de si enquanto crossdressers e para sua inserção social no BCC. Contudo, é a passagem por ambos (em especial do virtual ao real sem, porém, abandonar o virtual) que denota que aquela associada tem um compromisso efetivo com a prática do cding e com as demais associadas do clube. Tanto das reais, as quais teoricamente sabem quem são e com quem compartilham suas vidas duplas $e$ segredos, quanto das virtuais, que podem precisar de auxílio e aconselhamento daquelas que estão há mais tempo no clube e/ou possuem mais experiência com a prática do crossdressing e suas 
"dores e delícias", além de estímulos para se tornarem também reais em algum momento próximo.

\section{Referências bibliográficas}

ARANHA FILHO, J. M. Tribos eletrônicas: usos \& costumes. In: Anais do Seminário preparatório sobre aspectos sócio-culturais da internet no Brasil. Rio de Janeiro, RNP, MCT, 1995.

BARBOSA, M. T. de M. A prática crossdresser na blogosfera: Um Estudo Baseado em Análise de Blogs Crossdressers. 2014. Dissertação (Mestrado) - Antropologia Social, Universidade Federal de Goiás.

FACCHINI, R. Entre umas e outras: mulheres (homo)sexualidades $e$ diferenças na cidade de São Paulo. 2008. Tese (Doutorado) Ciências Sociais, Universidade Estadual de Campinas.

GOFFMAN, E. A representação do eu na vida cotidiana. 13 ed. Petrópolis, Vozes, 2005.

GOFFMAN, E. Estigma: notas sobre a manipulação da identidade deteriorada. Rio de Janeiro, Zahar, 1975.

GOMES, L. G.; LEITAO, D. K. Estar e não estar lá, eis a questão: pesquisa etnográfica no Second Life. Cronos, Natal, vol.12, nº 1, jan.jun. 2011, pp.25-40.

GRUNVALD, V. "Sexy Sensual sempre... vulgar JAMAIS": erotismo, moralidade e (homo)sexualidade na prática de crossdressing. Artigo apresentado no III Encontro do Núcleo de Estudos sobre Marcadores Sociais da Diferença na Universidade de São Paulo, 2014.

LEITÃO, D. K. Sexualidade e mercado erótico no mundo virtual Second Life. $36^{\circ}$ Encontro Anual da ANPOCS, GT 32: Sexualidade e gênero: sociabilidade, erotismo e política. Anais... Águas de Lindóia, 2012.

LÉvY, P. Cibercultura. São Paulo: Editora 34, 2005.

LÉVY, P. O que é virtual? São Paulo: Editora 34, 1996.

MAXIMO, M. E.; LACERDA, J. de S.; RIFIOTIS, T. Nas fronteiras entre o "online" e o "off-line": notas para um estudo etnográfico das formas de apropriação dos centros públicos de acesso à internet. Intercom Sociedade Brasileira de Estudos Interdisciplinares da Comunicação/IX 
390 Entre "reais"e "virtuais"...

Congresso de Ciências da Comunicação na Região Sul. Anais... Guarapuava, 2008.

MISKOLCI, R. San Francisco e a nova economia do desejo. Lua Nova, 91, São Paulo, 2014, pp.269-295.

. Networks of desire: the specter of AIDS and the use of digital media in the quest for secret same-sex relations in São Paulo. Vibrant, Virtual Braz. Anthr., Brasília, vol. 10, nº 1, June 2013, pp. 40-70.

- Novas conexões: notas teórico-metodológicas para pesquisas sobre o uso de mídias digitais. Cronos, Natal, vol. 12, n² 2 , jul./dez. 2011, pp.9-22.

PADILHA, F. O segredo é a alma do negócio: Mídias digitais móveis e a gestão da visibilidade do desejo homoerótico masculino na região de São Carlos. Artigo apresentado no III Encontro do Núcleo de Estudos sobre Marcadores Sociais da Diferença na Universidade de São Paulo, 2014.

PeRlongher, N. O negócio do michê: prostituição viril em São Paulo. 2 ed. São Paulo, Brasiliense, 1987.

Primo, A. F. T.; Pereira, V. A.; Freitas, A. Brazilian Crossdresser Club. CyberPsychology \& Behavior 3(2), abril 2000, pp.287-296.

VenCATO, A. P. Sapos e princesas: prazer e segredo entre praticantes de crossdressing no Brasil. São Paulo, Annablume, 2013.

Negociando desejos e fantasias: corpo, gênero, sexualidade $e$ subjetividade em homens que praticam crossdressing. In: DíAzBeniteZ, M. E.; FIgARI, C. E. (Org.). Prazeres dissidentes. Rio de Janeiro, CLAM - Garamond, 2009a, pp.93-117.

. Existimos pelo prazer de ser mulher: uma análise do Brazilian Crossdresser Club. 2009b. Tese (Doutorado) - Antropologia, Universidade Federal do Rio de Janeiro.

ZILLI, B. D. A perversão domesticada: Estudo do discurso de legitimação do BDSM na Internet e seu diálogo com a Psiquiatria. 2007. Dissertação (Mestrado) - Saúde Coletiva, Universidade do Estado do Rio de Janeiro. 